\title{
Processing of Lyocell Fiber Mat: An Alternative Renewable Reinforcement in Composite Manufacturing
}

\author{
Kayode Feyisetan Adekunle ${ }^{1,2 *}$, Mikael Skrifvars ${ }^{2}$ \\ ${ }^{1}$ Department of Chemical Engineering, Michael Okpara University of Agriculture, Umudike, Nigeria \\ ${ }^{2}$ Polymer Group, School of Engineering, University of Boras, Boras, Sweden \\ Email: ${ }^{*}$ kayode.adekunle@hb.se, ${ }^{*}$ k adekunle@yahoo.co.uk
}

Received 18 February 2015; accepted 7 April 2015; published 8 April 2015

Copyright (C) 2015 by authors and Scientific Research Publishing Inc.

This work is licensed under the Creative Commons Attribution International License (CC BY). http://creativecommons.org/licenses/by/4.0/

(c) (i) 0 pen Access

\section{Abstract}

The carding of the Lyocell cellulose fiber was done with a cylindrical cross lap machine supplied by Cormatex Prato, Italy. Several mats were made by carding and needle punching in order to have a compact and well entangled mat suitable for reinforcement. The speed of the cross lap machine, the frequency of needle punching, the number of times the mat goes through needle punching, the feeding rate of the carded fiber and the depth of needle penetration determined the level of entanglement of the Lyocell fiber which ultimately increased the mechanical properties of the fiber. The good mechanical properties of the carded Lyocell fiber made it a renewable and environmentally friendly alternative as reinforcement in composite manufacturing. Compared with other jute fiber reinforced composites, the mechanical properties of the resulting Lyocell composites were found to be better. Regenerated cellulose fiber (Lyocell) composites were environmentally friendly and the mechanical properties were comparable to those of natural fibers.

\section{Keywords}

Cellulose Fiber, Environmentally Friendly, Lyocell Fiber, Composites, Mechanical Properties

\section{Introduction}

Lyocell is a regenerated cellulose fiber derived from bleached wood pulp. Lyocell is obtained by a solvent spinning technique, using $\mathrm{N}$-methylmorpholine $\mathrm{N}$-oxide as the solvent. The spinning process is simpler and more environmentally sound than the Viscose spinning process, since it uses a solvent that is less toxic than the carbon

\footnotetext{
*Corresponding author.
} 
disulfide used in the Viscose process, and since it can also be recycled in the manufacturing process [1]. The regenerated cellulose fibers are of interest in structural composites, as they represent chemically pure cellulose fibers with an even quality and performance that cannot be achieved with mechanically treated natural fibers such as flax and hemp [1].

A comprehensive review of bio-fibers and bio-composites has also been published by John et al. [2] Carrillo et al. reported the properties of a conventional thermoplastic reinforced with Lyocell fiber [3] also, hybrid composites of jute and man-made cellulose fiber with polypropylene have been reported by Khan et al. [4] but quite little has been reported on Lyocell fiber-reinforced bio-based thermosetting polymers.

Textile-reinforced composites based on natural fibers have been studied by many research groups in recent years due to their good mechanical performance, excellent drape ability, easy handling, excellent integrity, conformability for advanced structural applications, and reduced manufacturing cost [5]. Woven fabrics have been found to be better than non-woven fibers as reinforcements, because the weave architectures of woven fabrics affect the permeability and the mechanical and fracture properties of the composite [5]. On the other hand, nonwoven mats with aligned fibers are of interest since they have no crimp, and are of low cost. Textile structural composites are finding use in various high-performance applications [6]. Bledzki and Zhang have reported the use of jute fabrics as reinforcement in the preparation of composites [7]. Different cellulose fibers have been studied by many researchers as reinforcement in various matrices [8] [9]. Various treatments can be done to these natural fibers to improve their wettability and consequently improve the fiber-matrix adhesion in the resulting composite. Many authors have done extensive work on natural fiber treatment [10]-[12].

A hybrid bio-based composite is a combination of the individual characteristics of at least two different types of natural fiber reinforcements in a single renewable matrix [1].

It is worthy to note that the use of Lyocell fiber in composite manufacturing has not really been explored. Many authors have worked on different types of natural fiber as alternatives to synthetic fiber but not much has been reported on another alternative renewable material such as regenerated cellulose fiber (Lyocell). This study shows that Lyocell fiber can compete with natural fibers as reinforcement in composite manufacturing. However, the combination of natural and Lyocell fibers (hybrid), significantly improves the mechanical properties of the composites.

\section{Experimental}

\subsection{Manual Separation of the Lyocell Fiber}

The fiber was supplied in lumps which made it difficult to be processed without mechanical or manual separation. The fiber was manually separated before being fed into the carding machine. Figure 1 shows the manually separated Lyocell fiber.

The separated fiber was fed into the inlet of the carding machine for processing, see Figure 2. The speed of the process of manufacturing will depend on various parameters which should be adhered to.

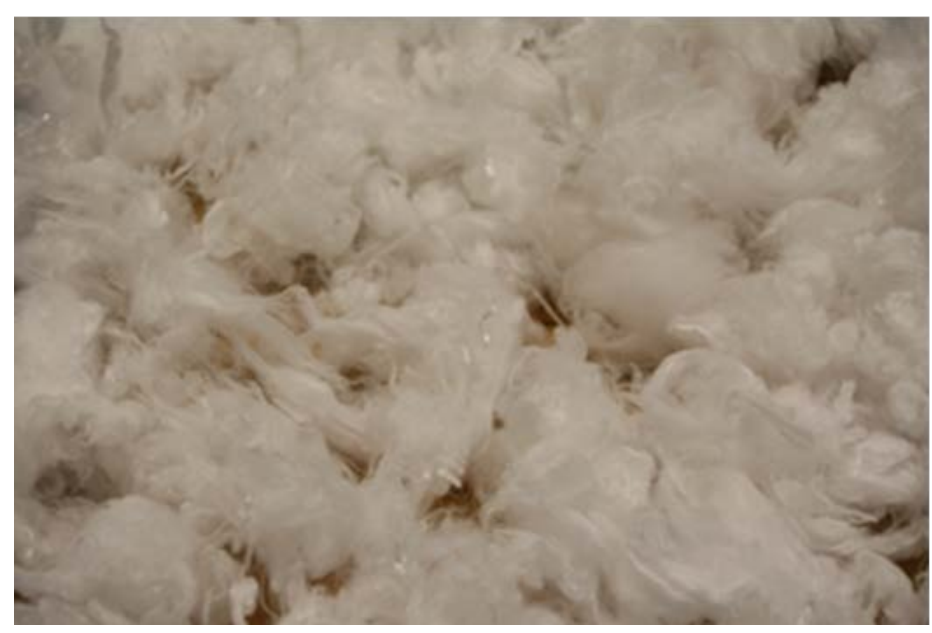

Figure 1. Manually separated Lyocell fiber. 


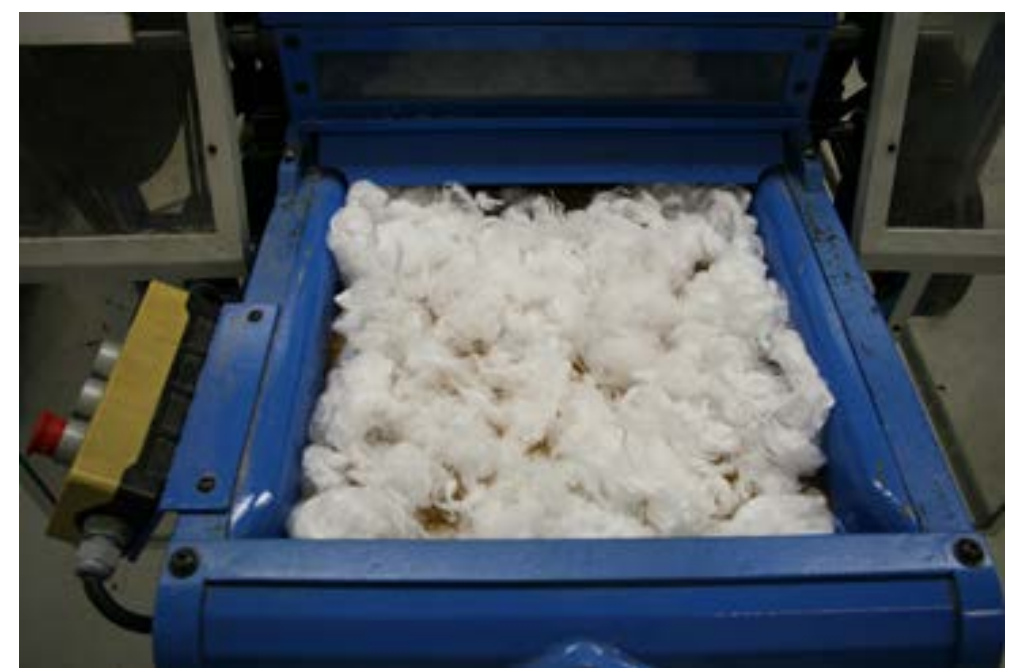

Figure 2. Lyocell fiber at the inlet of the carding machine.

\subsection{Carding of the Lyocell Fiber}

The carding of the Lyocellcellulose fiber was done with a cylindrical cross lap machine supplied by Cormatex Prato, Italy (see Figure 3). The cellulose fiber were separated manually and fed into the carding machine as explained above. The frequency of the trolley was $40 \mathrm{~Hz}$ which is equivalent to $7.5 \mathrm{~m} / \mathrm{min}$ at the outlet.

The semi processed Lyocell fiber came out of the outlet as a mat but not compact as it should be. Figure 4 shows the outlet of the carding machine. The volume of the processed fiber can be determined by adjusting the space for the cross lap and by feeding the machine continuously.

The total processing time of the Lyocell fiber inside the carding machine depends on the thickness of the fiber mat to be achieved at the end of the process. The thickness of the carded mat is also a function of the amount of manually separated fiber fed into the machine. High volume of separated fiber is recommended for easy handling.

\subsection{Needle Punching of the Lyocell Fiber}

The needle punching was done with a frequency of $200 \mathrm{cp} / \mathrm{min}$ and the feeding rate was $1.5 \mathrm{~m} / \mathrm{min}$ while the depth of the needle was $8 \mathrm{~mm}$. The needle punching machine was supplied by CertecSourcieux Les mines, France. See Figure 5.

Needle penetration depth and frequency contributed to the entanglement of the fiber. The frequency is related to the feeding speed, the more the needle punching the stiffer the material obtained. In this case the needle punching was done three times. The surface weight of the carded Lyocell mat was $525 \mathrm{~g} / \mathrm{m}^{2}$.

The thickness of the fiber can ultimately be determined with the needle punch machine. The higher the frequency of the needle punching is, the better the quality of the mat is and the better the mechanical properties of the composite are. The needle punching gives the fiber mat better entanglement. For the purpose of composite manufacturing the more entangle the material is the better the mechanical properties particularly the tensile strength.

\subsection{The Carded Lyocell Mat}

The processed Lyocell mat (Figure 6) can be used as reinforcement composite manufacturing. It is renewable and environmental friendly. Compatibility of the mat with vegetable oil-based polymers makes the composites manufactured a good candidate for construction and automotive applications. It is easy to handle and quite neat to work with. Several layers can be used in reinforcement.

The Lyocell fibre produced in this study has been used in composite and hybrid composite manufacturing by Adekunle et al. [1]. The mechanical and viscoelastic properties of soybean oil thermoset reinforced with jute fabrics and carded Lyocell fiber were determined and comparisons were made. The Lyocell fiber is also compatible with natural fiber which means that it can be blended with natural fiber for increased mechanical properties. 


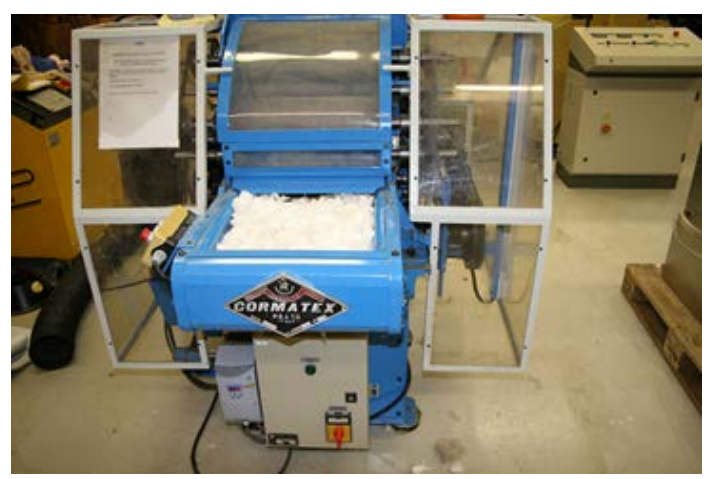

Figure 3. In-let of the carding machine.

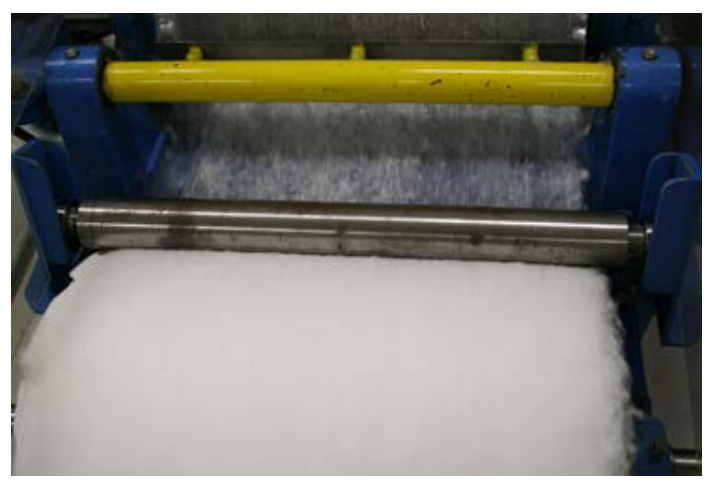

Figure 4. Outlet of the carding machine.
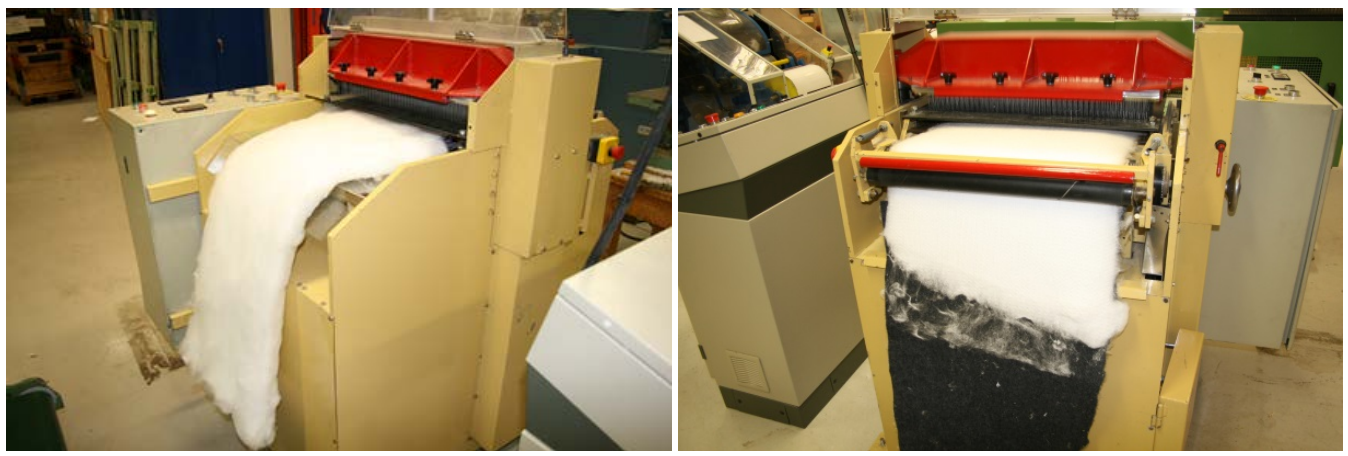

Figure 5. Inlet and outlet of the Needle punching machine.
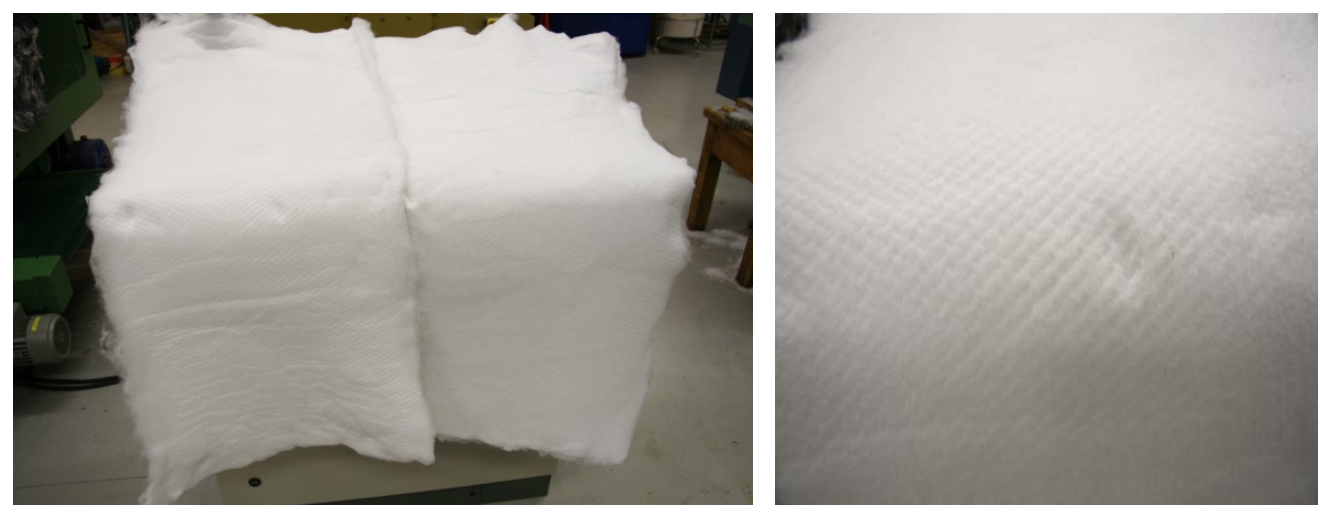

Figure 6. Carded and needled Lyocell mats. 
Adekunle et al. [1] in their study manufactured composites and hybrid composites using the Lyocell fiber produced in this article. Three different types of jute fabrics with biaxial weave architecture but different surface weights, and carded Lyocell fiber were used as reinforcements. Hybrid composites were also manufactured by combining the jute reinforcements with the Lyocell.

\section{Discussion of Results}

Mechanical properties of the Lyocell reinforced composites have been extensively discussed by Adekunle et al. [1], this study focus on the processing techniques of the carded Lyocell fiber but the mechanical properties of the resulting Lyocell reinforced composites were extracted from the earlier published paper in other to give credence to the suitability of using Lyocell fiber as a renewable reinforcement. Below are the results of the mechanical properties of the soybean oil thermoset reinforced Lyocell fiber composites as compared with jute fabric reinforced composites.

\subsection{Tensile Strength}

Composites reinforced with jute woven fabric of $240 \mathrm{~g} / \mathrm{m}^{2}$ surface weight were denoted with W1, those with woven fabric with a surface weight of $300 \mathrm{~g} / \mathrm{m}^{2}$ were denoted with $\mathrm{W} 2$, those with woven fabric with a surface weight of $100 \mathrm{~g} / \mathrm{m}^{2}$ were denoted with W3, and the Lyocell-reinforced composite was denoted with L. The hybrid composites from the woven fabric/Lyocell were denoted as follows: W1L, W2L, and W3L.

The tensile strength of this composite was found to be almost double those of the other composites (see Figure 7). Although the Lyocell is non-woven, the three times needle punching of the carded mat might have imparted higher mechanical properties on the fiber which then gave better tensile strength to the resulting composite [1].

The tensile strength of the Lyocell reinforced composite $(\mathrm{L})$ is about 144 MPa compared to other composites and hybrid composites which is less than $100 \mathrm{MPa}$. The Lyocell composite (L) had a superior tensile strength of about $144 \mathrm{MPa}$, which indicated that this composite was the toughest and strongest (see Figure 7). The direction of carding was taken to be the fiber direction in the case of the Lyocell fiber, and this might have also contributed to the better tensile properties.

\subsection{Elongation}

The percentage elongation (Figure 8) for the jute fiber-reinforced composites was about $0.5 \%$ on the average. The percentage elongation for the Lyocell-reinforced composite $(\mathrm{L})$ was about $1.3 \%$; this was to be expected, due to the morphology of the regenerated cellulose fiber. This is evident in the higher tensile and flexural strengths and also in the high impact resistance.

\subsection{Tensile Modulus}

The Lyocell reinforced composites also showed appreciable tensile modulus compared to jute reinforced fibers (see Figure 9)

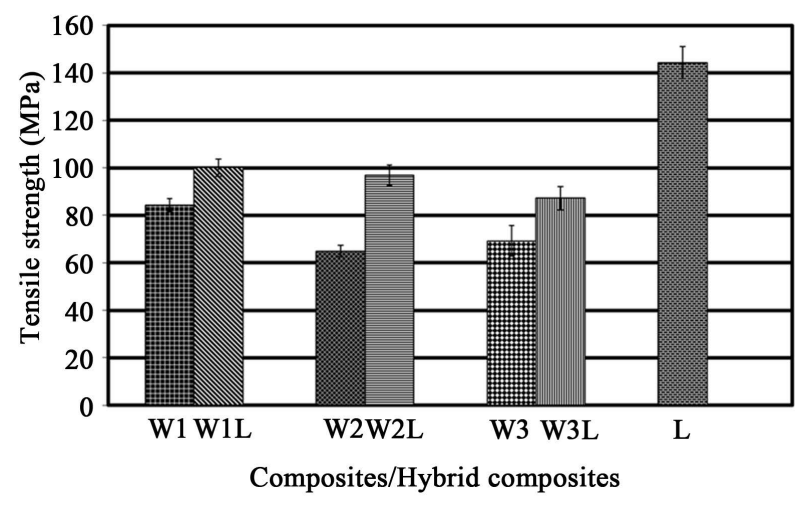

Figure 7. Tensile strength comparison of the composites and the hybrid composites [1]. 


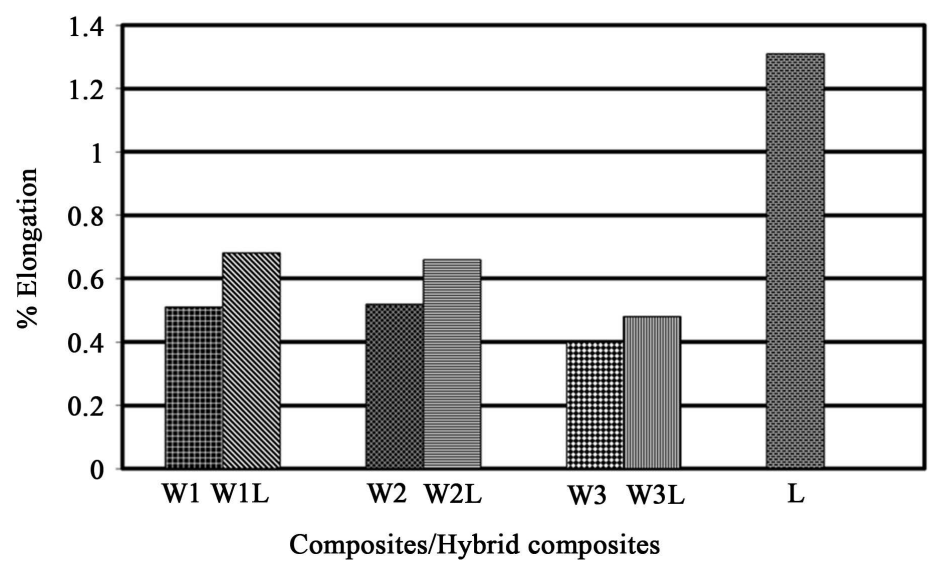

Figure 8. Percentage elongation [1].

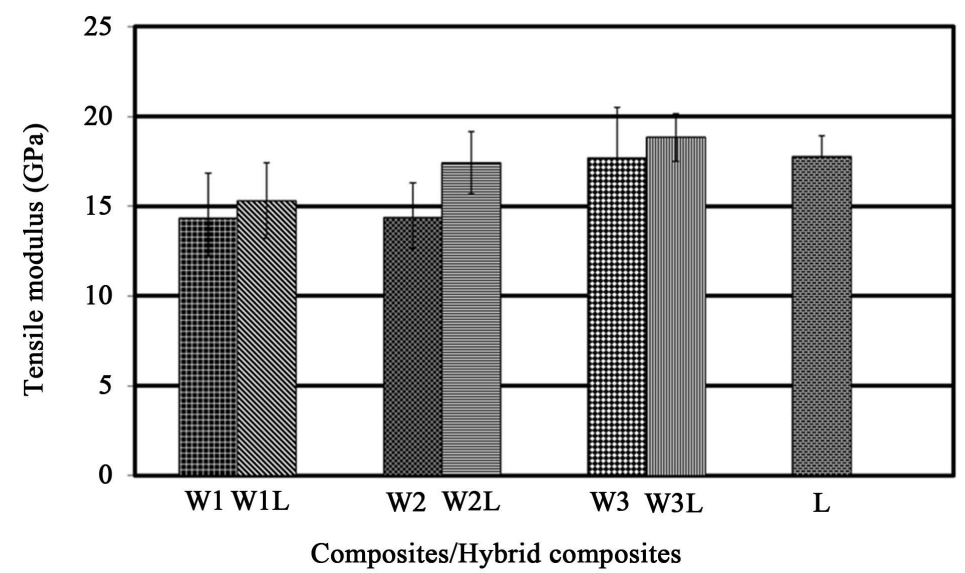

Figure 9. Tensile moduli of the jute and Lyocell composites compared with those of the jute/Lyocell hybrid composites [1].

\subsection{Flexural Strength}

Figure 10 shows the flexural strength of the composites. The Lyocell-reinforced composite L showed the highest flexural strength of about $217 \mathrm{MPa}$ compared with others having less than $150 \mathrm{MPa}$.

\subsection{Flexural Modulus}

The Lyocell reinforced composite had the highest flexural modulus of about 13 GPa (Figure 11).

\section{Conclusions}

Carded Lyocell fiber mat alone will not give the desiredmechanical properties, although the fiber is aligned but it looks week without entanglement. Needle punching gives better entanglement and makes the fiber to be more compact.

Regenerated cellulose fiber i.e. Lyocell fiber can be a good alternative to natural and synthetic fibers. The mechanical properties of the Lyocell fiber can be improved by increasing the frequency of the needle punch and also by needle punching more than two times. The production process of regenerated cellulose fiber (Lyocell) is environmentally friendly and thus makes it a good alternative to synthetic fibers.

The composites manufactured using the Lyocell fiber were found to have better mechanical properties than those of the jute fiber reinforced composites. It has tensile strength and modulus of about $144 \mathrm{MPa}$ and $18 \mathrm{GPa}$, respectively. The Lyocell-reinforced composite showed the highest flexural strength and modulus, of about 217 $\mathrm{MPa}$ and $13 \mathrm{GPa}$, respectively. The overall mechanical properties of natural fiber composites can also be im- 


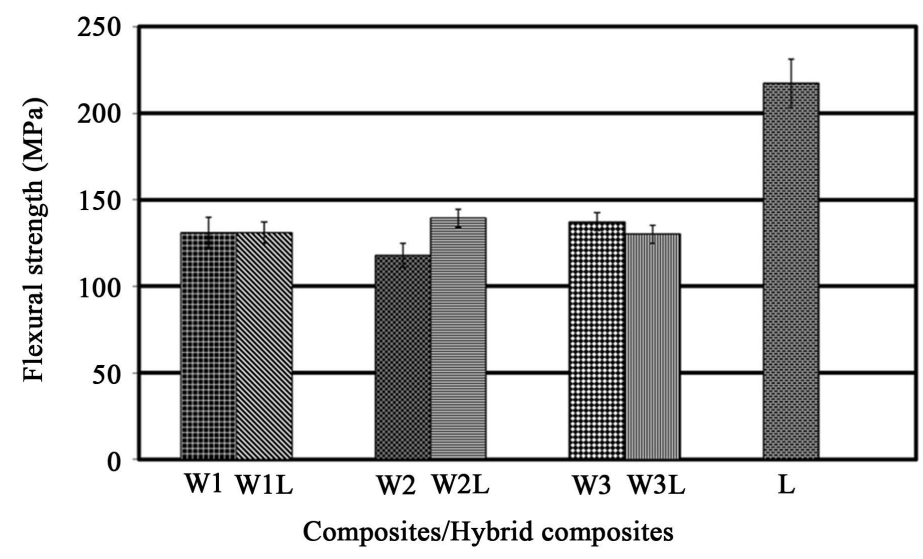

Figure 10. Flexural strength comparison of the composites and the hybrid composites [1].

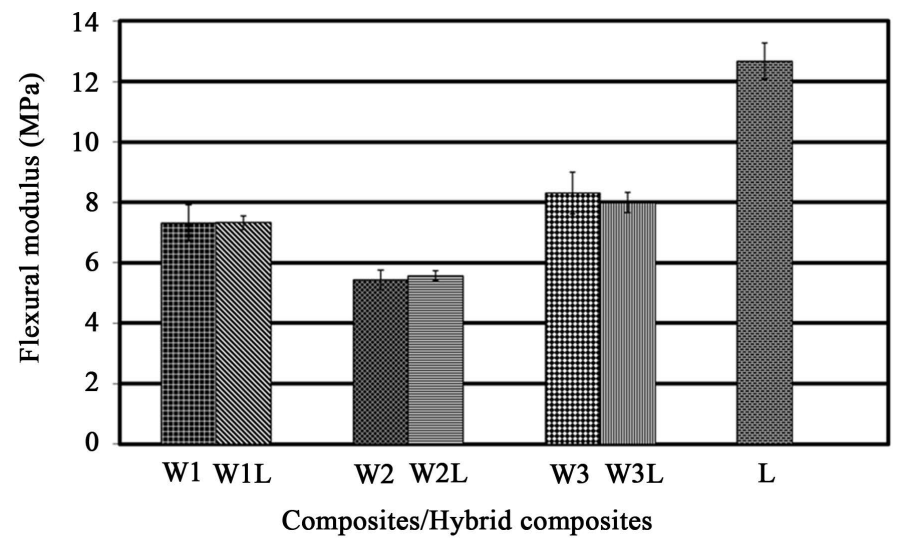

Figure 11. Flexural modulus comparison of the composites and the hybrid composites [1].

proved by blending with Lyocell fiber. Frequency of needle punching and the depth of the needle increase the entanglement of the Lyocell fiber mat.

\section{References}

[1] Adekunle, K.F., Patzelt, C., Kalantar, A. and Skrifvars, M. (2011) Mechanical and Viscoelastic Properties of Soybean Oil Thermoset Reinforced with Jute Fabrics and Carded Lyocell Fiber. Journal of Applied Polymer Science, 122, 28552863. http://dx.doi.org/10.1002/app.34360

[2] John, M.J. and Thomas, S. (2008) Biofibres and Biocomposites. Carbohydrate Polymers, 71, 343-364. http://dx.doi.org/10.1016/j.carbpol.2007.05.040

[3] Carrillo, F., Colom, X. and Canavate, X. (2010) Properties of Regenerated Cellulose Lyocell Fiber Reinforced Composites. Journal of Reinforced Plastics and Composites, 29, 359-371. http://dx.doi.org/10.1177/0731684408097777

[4] Khan, M.A., Ganster, J. and Fink, H.P. (2009) Hybrid Composites of Jute and Man-Made Cellulose Fibers with Polypropylene by Injection Moulding. Composites Part A: Applied Science and Manufacturing, 40, 846-851. http://dx.doi.org/10.1016/j.compositesa.2009.04.015

[5] Li, Y., Sreekala, M.S. and Jacob, M. (2009) Textile Composites Based on Natural Fibers. Old City Publishing (Chapter 8), Philadelphia 202-227.

[6] Pandita, S.D., Falconet, D. and Verpoest, I. (2002) Impact Properties of Weft Knitted Fabric Reinforced Composites. Composites Science and Technology, 62, 1113-1123. http://dx.doi.org/10.1016/S0266-3538(02)00057-X

[7] Bledzki, A.K. and Zhang, W. (2001) Dynamic Mechanical Properties of Natural Fiber-Reinforced Epoxy Foams. Journal of Reinforced Plastics and Composites, 20, 1263-1274. http://dx.doi.org/10.1177/073168401772679192 
[8] Pothan, L.A., Mai, Y.W., Thomas, S. and Li, R.K.Y. (2008) Tensile and Flexural Behavior of Sisal Fabric/Polyester Textile Composites Prepared by Resin Transfer Molding Technique. Journal of Reinforced Plastics and Composites, 27, 1847-1866. http://dx.doi.org/10.1177/0731684408090342

[9] Van de Weyenberg, I., Chi, T.T., Vangrimde, B. and Verpoest, I. (2006) Improving the Properties of UD Flax Fiber Reinforced Composites by Applying an Alkaline Fiber Treatment. Composites Part A: Applied Science and Manufacturing, 37, 1368-1376. http://dx.doi.org/10.1016/j.compositesa.2005.08.016

[10] Mohanty, S. and Nayak, S.K. (2006) Mechanical and Rheological Characterization of Treated Jute-HD Composites with a Different Morphology. Journal of Reinforced Plastics and Composites, 25, 1419-1439. http://dx.doi.org/10.1177/0731684406066676

[11] Khan, M.A. and Bhattacharia, S. (2007) Effect of Novel Coupling Agent on the Mechanical and Thermal Properties of Unidirectional Jute-Vinyl Ester Composites. Journal of Reinforced Plastics and Composites, 26, 617-627. http://dx.doi.org/10.1177/0731684407075563

[12] Gassan, J. and Bledzki, A.K. (1999) Possibilities for Improving the Mechanical Properties of Jute/Epoxy Composites by Alkali Treatment of Fibres. Composites Science and Technology, 59, 1303-1309. http://dx.doi.org/10.1016/S0266-3538(98)00169-9 